\title{
Editorial
}

\section{The Special Issue on Astrobiology in the UK}

\author{
M.J. Burchell ${ }^{1}$ and H.G.M. Edwards ${ }^{2}$ \\ ${ }^{1}$ Centre for Astrophysics and Planetary Sciences, School for Physical Science, University of Kent, Canterbury, \\ Kent CT2 $7 N R, U K$ \\ ${ }^{2}$ Chemical and Forensic Sciences, University of Bradford, Bradford BD7 1DP, UK
}

This issue of the International Journal of Astrobiology is devoted to papers from the astrobiology community in the United Kingdom. Twelve papers are presented in this issue, on topics ranging from pure science to science education. The call for papers was organised through the Astrobiology Society of Britain.

The Astrobiology Society of Britain has existed since Spring 2003, and is a continuation of an earlier group (the Astrobiology Forum) which had served for several years to help provide a national voice for UK researchers in the field. The Forum grew out of a meeting of UK researchers in the field, held in 1998 at the Royal Society in London. The meeting was sponsored by the British National Space Centre (BNSC), which then encouraged the setting up of an ad-hoc panel. The panel prepared a report (Astrobiology in the UK, pub. BNSC, 1999) which summarised the then state of UK research in this field. The panel then continued its work and developed into the Astrobiology Forum, which both publicised and encouraged UK research in the field, and also arranged representative links on various international bodies devoted to astrobiological research. The Forum's activities in encouraging the subject in the UK, culminated in the organising of a 3 day astrobiology conference in Cambridge in 2003. At this meeting (attended by approximately 80 delegates), it was decided to re-constitute the Astrobiology Forum into a proper society, with subsequently some 65 members in its first year. The members were very pleased when Sir Martin Rees, FRS and Astronomer Royal, agreed to be its Honorary President.

The membership of the society covers a range of research interests in astrobiology, with researchers from fields such as oceanography, Antarctic research, microbiology, chemistry, meteoritics, space science, astronomy and science education. This current issue of IJA provides a snapshot of the range of scholarly work that is currently underway in the UK in this field. The papers include: technical papers on how to develop instrumentation for future space missions, development of ideas about where to look for life, a review of Panspermia (a subject with a long traditional in the UK), calculational based papers presenting results on specific matters relating to processes of relevance to astrobiology, and so on.

The Society plans another national conference devoted to astrobiology in late 2005. As details become fixed, they will appear on the Society's website at: http://www.astrobiologysociety.org/. The same site includes all the abstracts of the talks presented at the 2003 meeting in Cambridge. It also includes details of how to apply to join the Society. 
We are grateful to the editors of IJA for agreeing this opportunity to showcase current research papers from the UK community. It reflects the growing international interest in the high quality work underway in the UK today in this rapidly developing field. 